\title{
Study of Adverse Events of Streptokinase Therapy in Patients with Acute ST Elevation Myocardial Infarction
}

\author{
Afifa Rahman*, Khairul Anam Mohammad Mahbub Hasan, Mosammat Umma Hanufa \\ Biomedical Engineering, Temple University, Philadelphia, USA \\ Email: *afifa.rahman99@gmail.com
}

How to cite this paper: Rahman, A., Hasan, K.A.M.M. and Hanufa, M.U. (2020) Study of Adverse Events of Streptokinase Therapy in Patients with Acute ST Elevation Myocardial Infarction. World Journal of Cardiovascular Diseases, 10, 500-508. https://doi.org/10.4236/wjcd.2020.107050

Received: June 20, 2020

Accepted: July 24, 2020

Published: July 27, 2020

Copyright $\odot 2020$ by author(s) and Scientific Research Publishing Inc. This work is licensed under the Creative Commons Attribution International License (CC BY 4.0).

http://creativecommons.org/licenses/by/4.0/

\begin{abstract}
Background: Despite of different adverse events, streptokinase (SK) is widely used to treat patients presented with acute ST segment elevation myocardial infarction. Objective: The purpose of the present study was to observe different adverse events in patients of acute ST segment elevation myocardial infarction receiving SK infusion. Methodology: This cross-sectional type of analytic observational study was carried out in the inpatient department of Cardiology at National Institute of Cardiovascular Diseases, Dhaka, Bangladesh from December $23^{\text {rd }} 2019$ to February $22^{\text {nd }} 2020$ for a period of two (2) months. All patients diagnosed as acute ST segment elevation myocardial infarction receiving SK were included in the present study. Adverse events were documented through completing a questionnaire by reviewing the records in the medical file as well as interviewing with the patients. Result: In this study, 43 (26.2\%) patients developed different types of adverse events and 121 (73.8\%) had no complications following SK infusion. The most common adverse event was hypotension i.e. $26(60.4 \%)$ and other adverse events were bleeding 8 (4.8\%) and allergic reaction 7 (4.2\%). Statistically significant higher rate of adverse events occurred in diabetic, hypertensive and dyslipidemia group which was 26 (56.5\%) Vs. 17 (14.4\%), $p=0.000,37$ (36.6\%) Vs. 06 (09.5\%), $p=0.000$ and 18 (54.5\%) Vs. 25 (19.1\%), $p=0.000$ respectively. The independent factors for the development of adverse events were smoking \{OR: 5.1 with $95 \%$ CI (1.7 to 15.1$), p=0.003$ \}, diabetes \{OR: 14.9 with $95 \% \mathrm{CI}$ (5.0 to 44.8 ), $p=0.000\}$, hypertension \{OR: 5.1with 95\% CI (1.7 to 15.1), $p=$ $0.003\}$ and dyslipidemia \{OR: 4.6 with $95 \%$ CI (1.5 to 13.7), $p=0.007\}$. Conclusion: Streptokinase infusion was associated with different adverse events. Among them the commonest one was hypotension and other less common events were minor bleeding and minor allergic reaction. The adverse events were more frequently documented in patients who were smoker, diabetic,
\end{abstract}


hypertensive and dyslipidemic.

\section{Keywords}

Adverse Events, Streptokinase, Acute ST Elevation Myocardial Infarction

\section{Introduction}

Worldwide acute myocardial infarction (AMI) is a major cause of mortality and morbidity and acute STEMI (ST-segment elevation myocardial infarction) is a medical emergency condition [1]. Although primary percutaneous coronary intervention (PCI) is the preferred treatment option [2] [3] for STEMI, the value of fibrinolytic therapy should not be overlooked in situations where primary PCI is not available or cannot be delivered in the appropriate timeframe [2] [4] [5]. Among different types of fibrinolytic agents, streptokinase (SK) is the most widely used agent especially in economically burdened countries due to the higher cost of the more effective recent generations of fibrinolytic such as tissue plasminogen activator (t-PA) [6].

SK is a metabolic product of beta-hemolytic streptococci and acts an indirect fibrinolytic agent. It interacts with plasminogen and forms an active complex with the protease activity that transforms plasminogen to plasmin [7]. Several large placebo-controlled trials illustrated the mortality benefit of SK in AMI patients [8] [9]. Despite the definite mortality benefits in AMI patients, SK infusion is associated with some adverse reactions such as allergic reactions, hypotension and bleeding. SK is a non-human protein which may cause severe anaphylactic responses including death [10] [11]. The severity of this immune response is dependent to the level of the anti-streptokinase antibodies in circulation [12] [13]. AMI is a clinical emergency and SK therapy is associated with several adverse events. Therefore, this study was performed to evaluate the pattern of adverse events induced by SK therapy and the association of adverse events with cardiovascular risk factors in patients with acute STEMI.

\section{Methodology}

This cross-sectional type of analytic observational study was carried out in the cardiology department of National Institute of Cardiovascular Diseases (NICVD) Hospital, Dhaka, Bangladesh from December $23^{\text {rd }} 2019$ to February $22^{\text {nd }} 2020$ for a period of two (2) months. All acute STEMI patients receiving Streptokinase in the cardiology department of NICVD during the study period were included in the present study. Patients who had cardiogenic shock, cardiac arrest at presentation, cirrhosis of liver, chronic kidney disease, bleeding disorders and history of SK infusion in the past were excluded from this study. Sample size was calculated by using appropriate formula i.e. sample size $n=\frac{z^{2} p q}{d^{2}}$. The sampling 
technique was purposive sampling and samples are included after vetting the inclusion and exclusion criteria. After taking detailed history, a thorough physical examination was performed, and STEMI was diagnosed by characteristic ischemic chest pain and electrocardiogram (ECG) criteria i.e. new ST elevation at the J point in at least 2 contiguous leads of $\geq 2 \mathrm{~mm}(0.2 \mathrm{mV})$ in men or $\geq 1.5 \mathrm{~mm}(0.15 \mathrm{mV})$ in women in leads $\mathrm{V}_{2}-\mathrm{V}_{3}$ and/or of $\geq 1 \mathrm{~mm}(0.1 \mathrm{mV})$ in other contiguous chest leads or the limb leads. The SK was administered in the coronary care unit (CCU) with the usual adult dose of AMI as 1,500,000 units intravenous infusion over $60 \mathrm{~min}$. Prior doses of $200 \mathrm{mg}$ Hydrocortisone and $12.5 \mathrm{mg}$ of Prochlorperazine Maleate were also given intravenously. Detection of adverse events were done through completing a questionnaire by reviewing the patients' medical file and documentation as well as interviewing with the patients. Data collection was conducted by researcher herself and her assistant as well. A systolic blood pressure of $<90 \mathrm{~mm}$ of $\mathrm{Hg}$ and a diastolic blood pressure of $<60 \mathrm{~mm}$ of $\mathrm{Hg}$ was recorded as hypotension. All data were compiled and edited meticulously by thorough checking and rechecking. All omissions and inconsistencies were corrected and were removed methodically. All data were recorded systematically in preformed data collection form (questionnaire) and quantitative data was expressed as mean and standard deviation and qualitative data was expressed as frequency distribution and percentage. Statistical analysis was performed by using SPSS for windows version $25.95 \%$ confidence limit was taken. Probability value $<0.05$ was considered as level of significance. Prior to the commencement of this study, the research protocol were approved by the ethical committee (Local Ethical committee) of NICVD. Informed consent was taken from the respondents prior to interview.

\section{Results}

During the 2 months study period, 164 patients who received SK were included in the study. The majority of patients were male $(n=140,85.4 \%)$. The mean age of study population was $54.7 \pm 11.2$ years old. In this study, $116(70.7 \%)$ of patients experienced the anterior MI and 48 (29.3\%) had inferior MI, respectively. Mean duration of chest pain was $383.6 \pm 327.1$ minutes and 130 (79.2\%) patients came within 360 minutes of the beginning of chest pain. Most of the patients, $103(62.8 \%)$ were obese and the mean BMI was $25.5 \pm 03.8 \mathrm{Kg} / \mathrm{M}^{2}$ (Table 1).

In this study, 76 (46.3\%), 101 (61.6\%), 46 (28.0\%) were smoker, hypertensive and diabetic respectively. 33 (20.1\%) and 63 (38.4\%) had dyslipidemia and family history of CAD respectively (Table 2).

In this research, 43 (26.2\%) patients noticed different types of adverse events and $121(73.8 \%)$ had no complications following SK infusion. The most common adverse event was hypotension i.e. 26 (60.4\%). No major bleeding event was recorded. Chills and rigor, 04 patients (57.1\%), was the commonest allergic event and no anaphylaxis was recorded as well (Table 3).

The frequency of adverse events was compared among different study subgroups. Statistically significant higher rate of adverse events occurred in diabetic, 
Table 1. Distribution of study population according to clinical parameters $(N=164)$.

\begin{tabular}{ccc}
\hline Clinical parameters & Mean & SD \\
\hline Age (Years) & 54.7 & 11.2 \\
Duration of chest pain (Minutes) & 383.6 & 327.1 \\
BMI (Kg/M ${ }^{2}$ & 25.5 & 03.8 \\
SBP (mm of Hg) & 122.9 & 18.9 \\
DBP (mm of Hg) & 78.8 & 13.1 \\
Pulse (Rates/Minute) & 82.7 & 12.2 \\
\hline
\end{tabular}

SD: Standard deviation; SBP: Systolic blood pressure; Hg: Mercury; BMI: Body mass index; DBP: Diastolic blood pressure.

Table 2. Distribution of study population according to gender and risk factors $(N=164)$.

\begin{tabular}{ccc}
\hline Gender/Risk factors & Frequency & Percentage (\%) \\
\hline Male & 140 & 85.4 \\
Female & 24 & 14.6 \\
Smoking & 76 & 46.3 \\
Hypertension & 101 & 61.6 \\
Diabetes & 46 & 28.0 \\
Dyslipidemia & 33 & 20.1 \\
Family history of CAD & 63 & 38.4 \\
\hline
\end{tabular}

CAD: Coronary artery disease.

Table 3. Frequency of adverse events of streptokinase among study population $(N=164)$.

\begin{tabular}{|c|c|c|c|}
\hline Study population & Number (\%) & $\begin{array}{l}\text { Number }(\%) \text { of adverse events } \\
\qquad(n=43)\end{array}$ & \\
\hline \multirow{7}{*}{$\begin{array}{l}\text { With adverse events } \\
=43(26.2 \%)\end{array}$} & $26(15.9 \%)$ & Hypotension 26 (60.4\%) & \\
\hline & $8(4.9 \%)$ & Bleeding 08 (18.7\%) & $\begin{array}{l}\text { Minor bleeding } 08(100 \%) \\
\text { Major bleeding } 00(0 \%)\end{array}$ \\
\hline & \multirow{4}{*}{$7(4.2 \%)$} & \multirow{4}{*}{ Allergic reaction 07 (16.3\%) } & Chills and rigor 04 (57.1\%) \\
\hline & & & Erythema $02(28.6 \%)$ \\
\hline & & & Wheezing 01 (14.3\%) \\
\hline & & & Anaphylaxis $00(0 \%)$ \\
\hline & $02(1.2 \%)$ & Cardiac arrest $02(4.6 \%)$ & \\
\hline No events & $121(73.8 \%)$ & & \\
\hline Total & $164(100 \%)$ & & \\
\hline
\end{tabular}

hypertensive and dyslipidemia group which was 26 (56.5\%) Vs. 17 (14.4\%), $p=$ 0.000, 37 (36.6\%) Vs. 06 (09.5\%), $p=0.000$ and 18 (54.5\%) Vs. 25 (19.1\%), $p=$ 0.000 respectively (Table 4$)$.

The multiple linear regression analysis was performed to determine the independent factors for the development of adverse events. The statistically significant 
Table 4. Comparison of adverse events of streptokinase among study subgroups.

\begin{tabular}{ccc}
\hline Study subgroups & Frequency of adverse events (\%) & $P$ value \\
\hline Male $(n=124)$ Vs. female $(n=24)$ & $36(25.7 \%)$ Vs. $07(29.2 \%)$ & $0.72^{\text {ns }}$ \\
Age $\geq 50$ years $(n=96)$ Vs. $<50$ years $(n=68)$ & $30(31.2 \%)$ Vs. $13(19.1 \%)$ & $0.24^{\text {ns }}$ \\
BMI $\geq 25(n=103)$ Vs. $<25(n=61)$ & $25(24.2 \%)$ Vs. 18 $(29.5 \%)$ & $0.82^{\text {ns }}$ \\
Chest pain $\geq 360 \mathrm{M}(n=34)$ Vs. $<360 \mathrm{M}(n=130)$ & $09(26.4 \%)$ Vs. 34 $(26.1 \%)$ & $0.88^{\text {ns }}$ \\
Smoker $(n=76)$ Vs. non-smoker $(n=88)$ & $18(23.7 \%)$ Vs.25 $(28.4 \%)$ & $0.49^{\text {ns }}$ \\
Diabetic $(n=46)$ Vs. non-diabetic $(n=118)$ & $26(56.5 \%)$ Vs. $17(14.4 \%)$ & $0.000^{\mathrm{s}}$ \\
Hypertensive $(n=101)$ Vs. normotensive $(n=63)$ & $37(36.6 \%)$ Vs. 06 $(09.5 \%)$ & $0.000^{\mathrm{s}}$ \\
Dyslipidemia $(n=131)$ Vs. no dyslipidemia $(n=33)$ & $18(54.5 \%)$ Vs. 25 $(19.1 \%)$ & $0.000^{\mathrm{s}}$ \\
F/H/O CAD present $(n=46)$ Vs. absent $(n=118)$ & $17(27.0 \%)$ Vs. 26 $(22.0 \%)$ & $0.73^{\text {ns }}$ \\
Anterior MI $(n=116)$ Vs. Inferior MI $(n=48)$ & $29(25.0 \%)$ Vs. 14 $(29.1 \%)$ & $0.66^{\text {ns }}$ \\
\hline
\end{tabular}

BMI: Body mass index; F/H/O: Family history of; MI: Myocardial infarction; s: Significant i.e. $P<0.05$; M: Duration in minutes; CAD: Coronary artery disease; ns: Non-significant i.e. $P \geq 0.05$.

Table 5. Multiple linear regression analysis between the number of adverse events and independent factors.

\begin{tabular}{cccc}
\hline Independent factors & $\boldsymbol{P}$ value & Odds ratio & 95\% confidence interval \\
\hline Smoking & $0.003^{\mathrm{s}}$ & 5.1 & 1.7 to 15.1 \\
Diabetes mellitus & $0.000^{\mathrm{s}}$ & 14.9 & 5.0 to 44.8 \\
Hypertension & $0.003^{\mathrm{s}}$ & 5.0 & 1.7 to 15.0 \\
Dyslipidemia & $0.007^{\mathrm{s}}$ & 4.6 & 1.5 to 13.7 \\
Family history of CAD & $0.594^{\mathrm{ns}}$ & 1.3 & 0.5 to 3.4 \\
Body mass index & $0.152^{\mathrm{ns}}$ & 0.5 & 0.2 to 1.2 \\
Age & $0.386^{\mathrm{ns}}$ & 1.5 & 0.6 to 4.0 \\
\hline
\end{tabular}

s: Significant; CAD: Coronary artery disease; ns: Non significant.

independent factors were smoking \{OR: 5.1 with $95 \%$ CI (1.7 to 15.1), $p=0.003\}$, diabetes \{OR: 14.9 with $95 \% \mathrm{CI}$ (5.0 to 44.8 ), $p=0.000$ \}, hypertension \{OR: 5.1 with $95 \% \mathrm{CI}$ (1.7 to 15.1$), p=0.003\}$ and dyslipidemia \{OR: 4.6 with $95 \% \mathrm{CI}$ (1.5 to 13.7$), p=0.007\}$ (Table 5).

\section{Discussion}

Although primary PCI is the gold standard in the management of reperfusion of the infarct-related artery of acute STEMI, the importance of fibrinolytic therapy cannot be exhausted especially a developing country like ours'. Fibrinolytic therapy when combined with Aspirin and Heparin significantly reduces the infarct size \{the major determinant of left ventricular (LV) function\}, and this has been translated into significantly lower mortality compared to the conservative treatment of this condition [14]. SK infusion has several well-known complications like hypotension and major and minor hemorrhagic events with standard 
SK regimen [15]. In this study, 43 (26.2\%) patients were recorded to have different types of adverse events and 121 (73.8\%) had no adverse event following SK infusion. Among the adverse events, most common complication was hypotension i.e. $26(60.4 \%)$. No major bleeding event was recorded. Chills and rigor, $04(57.1 \%)$, was the commonest allergic event and no anaphylaxis was recorded as well.

In our study, 26 (15.9\%) patients developed hypotension. This finding was slightly higher from some of the large trial like ISIS- 2 where the number of hypotension events were 1719 (10\%) [9]. Multiple factors might be responsible for this difference like single centered study, small sample size and purposive sampling technique. Shojaie and Abdi on the other hand, reported that hypotension and arrhythmia were the most commonly observed adverse events following SK infusion [16]. Unlike their study, arrhythmia was not so commonly documented. Two possible explanations may be considered, the mean age of the above study was higher in comparison to our study i.e. $61.7 \pm 11.7$ vs. $54.7 \pm 11.2$ and the ECG monitoring for several hours following SK infusion was not done routinely in our CCU. Premature ventricular contraction was the leading arrhythmia reported in the different studies and in most of the cases they were benign and reverted spontaneously. Different studies have documented that the hypotension following SK infusion was transient and improved following stoppage of infusion without any active measure in half of the cases [14]. The possible mechanism of hypotension is bradykinin mediated vasodilatation with peripheral pooling of the blood and this effect may be beneficial in patients of AMI presented acute heart failure. In some studies it was observed that the in hospital mortality was slightly lower in patients of AMI with acute heart failure receiving SK infusion [17].

Another common adverse event associated with streptokinase therapy is hemorrhage. In the present study 8 (4.9\%) out of 164 patients developed bleeding. This finding is consistent with two major SK administration trials, GISSI-l (1986) and ISIS-2 (1988) trials, where 515 (3.6\%) of the 14,452 patients developed bleeding. Most of the bleeding developed in the skin and subcutaneous tissue. Other less common sites are urinary, gastrointestinal and upper respiratory tract. Unlike our study, major bleeding requiring transfusion occurred in only $65(0.4 \%)$ of streptokinase recipients in the combined trials, compared with $0.2 \%$ in the ISIS-2 placebo group [8] [9]. The reasons behind the absence of major bleeding in our study are relatively younger mean age, small sample size and purposive sampling technique. Importantly, while the risk of cerebrovascular events is increased in the elderly, neither study noted a significant difference in hemorrhagic complications in older as opposed to younger patients receiving streptokinase therapy. Moreover, although the combination of heparin with streptokinase increased the risk of bleeding in the ISIS-2 trial, concomitant use of aspirin did not. In placebo-controlled trials, the incidence of cerebrovascular events following streptokinase therapy has varied from $0.1 \%$ to $1 \%$ [8] [9], with 
the ISIS-2 trial demonstrating an incidence for intracranial bleeding and stroke of $0.1 \%$ and $0.7 \%$, respectively. While a significant $(p<0.02)$ increase in "early" hemorrhagic or other strokes occurred up to 1 day after streptokinase treatment, the overall risk of stroke in the ISIS-2 study was comparable in streptokinaseand placebo-treated patients ( $0.7 \%$ vs. $0.8 \%$, respectively). Addition of aspirin further lowered the overall incidence of stroke in streptokinase recipients $(0.6 \%)$ compared with patients receiving neither treatment (1.1\%). On the basis of these data, there does not appear to be a clinically significant increased risk of stroke during streptokinase therapy in elderly patients with acute myocardial infarction.

As streptokinase is a streptococcal protein, potentially serious allergic reactions are possible but rare. No confirmed cases of anaphylactic shock were reported in the 8592 streptokinase recipients in the ISIS-2 trial. Minor allergic reactions, consisting of shivering, pyrexia or rashes, occurred in $4.4 \%$ of patients at the time of streptokinase infusion compared with $0.9 \%$ receiving placebo [9]. This finding is very much comparable to our study where 7 (4.2\%) out of 164 respondents noticed minor allergic events. In contrast, the GISSI-1 study (1986) reported 7 cases of nonfatal anaphylactic reactions in 5860 patients receiving streptokinase, with 99 patients $(1.7 \%)$ who experienced allergic reactions being withdrawn from therapy [8]. In the ISIS-3 trial the majority of allergic reactions associated with streptokinase administration were minor, and while these were less commonly reported than in the anistreplase group (3.6\% vs. $5.1 \%$, respectively; $2 p<0.00001$ ), they were significantly more common than in the recombinant tissue Plasminogen Activator (rt-PA) group (3.6\% vs. $0.8 \%$, respectively; $2 p<0.00001)$. Approximately one-tenth of these reactions caused persistent symptoms $(0.3 \%$ vs. $0.5 \%$ vs. $0.1 \%$ for streptokinase, anistreplase and rt-PA, respectively; $2 p<0.002$ ) [18]. Findings from GUSTO agree with these conclusions, demonstrating a significantly greater incidence of anaphylaxis with streptokinase $(0.6 \%$ and $0.7 \%)$ than with rt-PA (0.2\%) [19]. Isolated cases of serum sickness-type disorders, Guillain Barre syndrome and Hennoch Schonlein syndrome was also reported following streptokinase therapy.

No case of death was documented in this study because only living patients following SK therapy were included and there was no follow up as well. The adverse events are significantly associated with patients who were diabetic, hypertensive and dyslipidemic. Another important finding was that the independent factors responsible for adverse events following SK therapy were smoking, diabetes mellitus, hypertension and dyslipidemia analyzed by multivariate regression analysis.

\section{Conclusion}

In can be concluded from the study that the commonest adverse event was hypotension. But other less common adverse events were minor bleeding and minor allergic reaction. The adverse events were more frequently documented in 
patients who were smoker, diabetic, hypertensive and dyslipidemic.

\section{Limitations}

There were also some limitations in this study. These are single centered study, small sample size, purposive sampling technique and every patient was not been observed during SK therapy by the researcher or her assistant.

\section{Funding}

This study has been performed without any funding from outside else.

\section{Contributions to Authors}

Hasan KAMM and Hanufa MU had involved in manuscript writing \& revision of the manuscript.

\section{Conflicts of Interest}

There was no conflict of interest to any of the authors.

\section{References}

[1] Isezuo, S., Subban, V., Krishnamoorthy, J., Pandurangi, U.M., Janakiraman, E., Kalidoss, L., et al. (2014) Characteristics, Treatment and One-Year Outcomes of Patients with Acute Coronary Syndrome in a Tertiary Hospital in India. Indian Heart Journal, 66, 156-163. https://doi.org/10.1016/j.ihj.2013.12.023

[2] O’Gara, P.T., Kushner, F.G., Ascheim, D.D., Casey, D.E., Chung, M.K., Lemos, J.A., et al. (2013) ACCF/AHA Guideline for the Management of ST-Elevation Myocardial Infarction: A Report of the American College of Cardiology Foundation/American Heart Association Task Force on Practice Guidelines. Circulation, 127, e362-e425. https://doi.org/10.1161/CIR.0b013e3182742c84

[3] Steg, P.G., James, S.K., Atar, D., Badano, L.P., Blömstrom-Lundqvist, C., Borger, M.A., et al. (2012) ESC Guidelines for the Management of Acute Myocardial Infarction in Patients Presenting with ST-Segment Elevation. European Heart Journal, 33, 2569-2619. https://doi.org/10.1093/eurheartj/ehs215

[4] Boersma, E., Maas, A.C.P., Deckers, J.W. and Simoons, M.L. (1996) Early Thrombolytic Treatment in Acute Myocardial Infarction: Reappraisal of the Golden Hour. The Lancet, 348, 771-775. https://doi.org/10.1016/S0140-6736(96)02514-7

[5] Weaver, W.D., Cerqueira, M., Hallstrom, A.P., Litwin, P.E., Martin, J.S., Kudenchuk, P.J., et al. (1993) Prehospital-Initiated vs Hospital-Initiated Thrombolytic Therapy. The Myocardial Infarction Triage and Intervention Trial. JAMA, 270, 1211-1216. https://doi.org/10.1001/jama.1993.03510100061033

[6] Simoons, M., Krzemiñska-Pakula, M., Alonso, A., Goodman, S., Kali, A., Loos, U., et al. (2002) Improved Reperfusion and Clinical Outcome with Enoxaparin as an Adjunct to Streptokinase Thrombolysis in Acute Myocardial Infarction. The AMI-SK Study. European Heart Journal, 23, 1282-1290. https://doi.org/10.1053/euhj.2001.3083

[7] Young, K.C., Shi, G.Y., Chang, Y.F., Chang, B.I., Chang, L.C., Lai, M.D., et al. (1995) Interaction of Streptokinase and Plasminogen. Studied with Truncated Streptokinase Peptides. Journal of Biological Chemistry, 270, 29601-29606. 
https://doi.org/10.1074/jbc.270.49.29601

[8] Gruppo Italiano Per Lo Studio Della (1986) Effectiveness of Intravenous Thrombolytic Treatment in Acute Myocardial Infarction. The Lancet, 327, 397-402. https://doi.org/10.1016/S0140-6736(86)92368-8

[9] ISIS-2 Investigators (1988) Randomised Trial of Intravenous Streptokinase, Oral Aspirin, Both, or Neither among 17,187 Cases of Suspected Acute Myocardial Infarction: ISIS-2. ISIS-2 (Second International Study of Infarct Survival) Collaborative Group. The Lancet, 2, 349-360. https://doi.org/10.1016/S0140-6736(88)92833-4

[10] Lee, H.S. (1995) How Safe Is the Readministration of Streptokinase? Drug Safety, 13, 76-80. https://doi.org/10.2165/00002018-199513020-00002

[11] Jennings, K. (1996) Antibodies to Streptokinase. BMJ, 312, 393-394. https://doi.org/10.1136/bmj.312.7028.393

[12] Bick, R.L. (1982) Clinical Relevance of Antithrombin III. Seminars in Thrombosis and Hemostasis, 8, 276-287. https://doi.org/10.1055/s-2007-1005058

[13] Collen, D. (1990) Coronary Thrombolysis: Streptokinase or Recombinant Tissue-Type Plasminogen Activator? Annals of Internal Medicine, 112, 529-538. https://doi.org/10.7326/0003-4819-112-7-529

[14] Gruppo Italiano per Lo Studio Della, Medical Science (1990) GISSI-2: A Factorial Randomised Trial of Alteplase versus Streptokinase and Heparin versus No Heparin among 12,490 Patients with Acute Myocardial Infarction. Gruppo Italiano per lo Studio della Sopravvivenza nell'Infarto Miocardico. The Lancet, 336, 65-71. https://doi.org/10.1016/0140-6736(90)91589-3

[15] Tatu-Chitoiu, G., Teodorescu, C., Dan, M., Capraru, P., Guran, M., Istratescu, O., et al. (2003) Efficacy and Safety of a New Streptokinase Regimen with Enoxaparin in Acute Myocardial Infarction. Journal of Thrombosis and Thrombolysis, 15, 171-179. https://doi.org/10.1023/B:THRO.0000011372.26594.01

[16] Shojaie, M. and Abdi, M.H. (2009) Survey Side Effect of Intravenous Streptokinase in Old Patients with Acute Myocardial Infarction. Journal of Jahrom University of Medical Sciences, 7, 7-14. https://doi.org/10.29252/jmj.7.4.2

[17] Battershill, P.E., Benfield, P. and Goa, K.L. (1994) Streptokinase. A Review of Its Pharmacology and Therapeutic Efficacy in Acute Myocardial Infarction in Older Patients. Drugs Aging, 4, 63-86. https://doi.org/10.2165/00002512-199404010-00007

[18] (1992) ISIS-3: A Randomised Comparison of Streptokinase vs Tissue Plasminogen Activator vs Anistreplase and of Aspirin plus Heparin vs Aspirin Alone among 41,299 Cases of Suspected Acute Myocardial Infarction. The Lancet, 339, 753-770. https://doi.org/10.1016/0140-6736(92)91893-D

[19] The GUSTO Investigators (1993) An International Randomized Trial Comparing Four Thrombolytic Strategies for Acute Myocardial Infarction. The New England Journal of Medicine, 329, 673-682. https://doi.org/10.1056/NEJM199309023291001 